\title{
BMJ
}

\section{Local anaesthesia for pain control during outpatient hysteroscopy: systematic review and meta-analysis}

\author{
Natalie A M Cooper, clinical research fellow Khalid S Khan, professor of obstetrics and gynaecology and \\ clinical epidemiology, honorary consultant obstetrician and gynaecologist T Justin Clark, consultant \\ obstetrician and gynaecologist and honorary senior lecturer
}

\section{ABSTRACT}

Objective To compare the effects of different types of local anaesthetic for pain control during outpatient hysteroscopy.

Design Systematic review and meta-analysis of randomised controlled trials.

Setting Outpatient hysteroscopy clinics.

Participants Women undergoing diagnostic or operative hysteroscopy as outpatients-that is, without general anaesthesia.

Study selection criteria Medline, Embase, CINAHL, the Cochrane library, and reference lists of relevant studies. Two reviewers independently selected trials. Data were abstracted on quality, characteristics, and results. Results There were 20 trials (2851 participants). Data from 15 of these were meta-analysed in subgroups defined by type of intervention and study quality. Intracervical (standardised mean difference $-0.36,95 \%$ confidence interval -0.61 to $\left.-0.10, \mathrm{I}^{2}=0 \%\right)$ and paracervical $(-1.28$, -2.22 to $-0.35, \mathrm{I}^{2}=97 \%$ ) injections of local anaesthetic significantly reduced the pain in women undergoing hysteroscopy as outpatients, whereas transcervical $\left(-0.11,-0.31\right.$ to $\left.0.10, \mathrm{I}^{2}=27 \%\right)$ and topical application $\left(-0.32,-0.97\right.$ to $\left.0.33, I^{2}=90 \%\right)$ did not. Meta-regression showed that paracervical injection was superior to the other anaesthetic methods $(P=0.04)$, a finding that was supported by the high quality subgroup of studies. Use of local anaesthetic did not have a significant effect on the incidence of vasovagal episodes $(P=0.09)$.

Conclusions Paracervical local anaesthetic injection is the best method of pain control for women undergoing hysteroscopy as outpatients.

\section{INTRODUCTION}

Ambulatory hysteroscopy is a safe, feasible, and accurate procedure for diagnosing intrauterine pathology. Provision of outpatient based diagnostic and operative services is gaining prominence as a standard of care, ${ }^{2}$ but the experience of pain can be a deterrent for patients offered outpatient diagnostic hysteroscopy. Individual studies examining the effect of local anaesthetics are often imprecise and provide conflicting results. ${ }^{3}$ Though a recent review examined the use of paracervical injection for cervical dilatation and uterine interventions in various obstetric and gynaecological procedures, ${ }^{4}$ there is no comprehensive review evaluating comparative effectiveness of the whole range of local anaesthetic methods for specific procedures.

We conducted a systematic review to determine the effects of various local anaesthetic techniques used for pain control during outpatient hysteroscopy.

\section{METHODS}

We conducted the review prospectively, devising a protocol based on widely documented methods. ${ }^{56}$

Data sources and searches

We conducted a comprehensive literature search to identify studies that evaluated the use of local anaesthetic to reduce pain during outpatient hysteroscopy. The databases searched included Medline (from 1950 to September 2008), Embase (from 1980 to September 2008), CINAHL (from 1981 to September 2008), and the Cochrane library. We used a combination of the keywords "hysteroscopy," "vaginoscopy," "local anaesthetic," and their associated medical subject headings (MeSH) to search Medline, Embase, and CINAHL. The Cochrane library was searched with the keywords "hysteroscopy and "anaesthetic." To ensure maximum sensitivity we placed no limits or filters on the searches. We also checked the reference sections of selected original articles for relevant papers and retrieved any that we thought were relevant but had not been retrieved by the database searches.

\section{Study selection}

Population - Included women were undergoing diagnostic or operative hysteroscopy as outpatients - that is, without general anaesthesia.

Intervention - Use of local anaesthetic for pain relief during the procedure (for example, intracervical block, paracervical block, local anaesthetic instilled into the cavity or applied to the ectocervix, fig 1) was compared with no intervention, placebo, oral analgesics, or conscious sedation.

Outcome-Our outcomes were assessment of pain (primary outcome) and vasovagal episodes (secondary outcome) associated with the procedure. 
Table 1| Methodological quality assessment (Jadad scoring system ${ }^{11}$ ) of studies included in systematic review of use of local anaesthetic during outpatient hysteroscopy

\begin{tabular}{|c|c|c|c|c|c|c|c|}
\hline Study & Randomised & $\pm 1^{*}$ & Double blind & $\pm 1^{*}$ & $\begin{array}{l}\text { Withdrawals } \\
\text { and dropouts }\end{array}$ & Total & $\begin{array}{c}\text { Quality } \\
\text { (>3=high) }\end{array}$ \\
\hline Al-Sunaidi ${ }^{36}$ & 1 & 1 & 0 & 0 & 1 & 3 & Low \\
\hline Bellati21 & 1 & 0 & 0 & 0 & 1 & 2 & Low \\
\hline Broadbent $^{27}$ & 1 & 1 & 1 & 1 & 1 & 5 & High \\
\hline $\begin{array}{l}\text { Cicinelli } \\
1997^{14}\end{array}$ & 1 & 1 & 1 & 1 & 1 & 5 & High \\
\hline $\begin{array}{l}\text { Cicinelli } \\
1998^{15}\end{array}$ & 1 & 1 & 1 & 1 & 1 & 5 & High \\
\hline Costello ${ }^{38}$ & 1 & 1 & 1 & 1 & 1 & 5 & High \\
\hline Davies $^{24}$ & 1 & 1 & 1 & 1 & 1 & 5 & High \\
\hline Esteve $^{35}$ & 1 & 0 & 1 & 1 & 1 & 4 & High \\
\hline Finikiotis $^{13}$ & 1 & -1 & 0 & 0 & 1 & 1 & Low \\
\hline Giorda $^{30}$ & 1 & 1 & 0 & 0 & 1 & 3 & Low \\
\hline Guida $^{22}$ & 1 & 1 & 0 & 0 & 1 & 3 & Low \\
\hline $\mathrm{Kabli}^{39}$ & 1 & 1 & 0 & 0 & 1 & 3 & Low \\
\hline Lau $1999^{16}$ & 1 & 1 & 1 & 1 & 1 & 5 & High \\
\hline Lau $2000^{32}$ & 1 & 1 & 1 & 1 & 1 & 5 & High \\
\hline Makris $^{25}$ & 1 & 0 & 0 & 0 & 1 & 2 & Low \\
\hline Sagiv $^{26}$ & 1 & 1 & 0 & 0 & 1 & 3 & Low \\
\hline Shankar ${ }^{33}$ & 1 & 1 & 0 & 0 & 1 & 3 & Low \\
\hline Soriano $^{34}$ & 1 & 1 & 1 & 1 & 1 & 5 & High \\
\hline Vercellini $^{37}$ & 1 & 1 & 0 & 0 & 1 & 3 & Low \\
\hline Wong $^{40}$ & 1 & 1 & 1 & 1 & 1 & 5 & High \\
\hline
\end{tabular}

* Refers to description of randomisation and blinding. If methods are described and are adequate study receives an extra quality point, if they are inadequate then quality point is deducted.

Study design —All included studies were randomised controlled trials.

Inclusion process - Two authors (NAMC and TJC) independently reviewed the titles and abstracts from the electronic literature searches and selected citations if they seemed to fulfil the selection criteria. The complete manuscripts of selected citations were then reviewed in full to determine inclusion or exclusion. Studies were excluded if numerical data assessing pain were not presented explicitly (for example, some papers displayed results graphically such that the mean pain scores could only be estimated from the graph and given this ambiguity were excluded from further analysis). We aimed to contact authors but were unable to do so in some instances ${ }^{7}$ or received no reply in others. ${ }^{8}$ When duplicate data were published, we included only the most up to date, larger series. Any disagreements about study eligibility were resolved by consensus. We assessed agreement between raters with the $\kappa$ statistic. ${ }^{9}$

\section{Data extraction}

One of the authors (NAMC) used a piloted extraction form to record data from the selected studies. Data were collected to determine study quality (the confidence that the trial design, conduct, and analysis has minimised or avoided biases in its treatment comparisons) ${ }^{10}$ according to Jadad's scoring method, which allowed us to calculate a quality score on a 5 point scale ${ }^{1112}$ (table 1 ). Papers that scored $>3$ points were considered to be of high quality. We also collected data regarding the intervention, technical aspects of the hysteroscopy, assessment of pain, and vasovagal attacks.

Studies varied in how they assessed pain. Some studies gave an overall pain score for the procedure. Others scored each of the steps separately (for instance, tenaculum application, administration of anaesthetic or placebo, insertion of the scope, inspection of uterine cavity, during the biopsy, and at intervals after the end of the procedure). When available we used the overall pain score for the meta-analysis, but when the individual steps were scored, and no overall score was given, we used the score relating to inspection of the uterine cavity. When scores were given only after the procedure, we used the most immediate score. About $20 \%$ of women experience vasovagal reactions during outpatient hysteroscopy, ${ }^{13}$ possibly caused by parasympathetic nerve stimulation during passage of instruments through the cervical canal. Blocking the nerves with local anaesthetic might reduce the incidence of attacks, ${ }^{714}$ but one study has shown conflicting results. ${ }^{16}$

To examine the incidence of vasovagal episodes in relation to use of local anaesthetics, we extracted data as $2 \times 2$ contingency tables (occurrence $v$ non-occurrence).

\section{Data synthesis}

We evaluated the effect of local anaesthetic on pain relief in outpatient hysteroscopy using standardised mean differences (SMD). This measure was chosen as it allowed comparison of outcome data from studies that used different scales to quantify pain. ${ }^{6}$

Heterogeneity was assessed by examining forest plots and the $\mathrm{I}^{2}$ statistic, which if greater than $75 \%$ suggests considerable heterogeneity. ${ }^{6}$ Meta-analysis was performed for data overall and by subgroups defined by type of intervention and study quality. We weighted studies by the inverse of the variance and used random effects models as standard as they give conservative estimates of effect. ${ }^{6} \mathrm{We}$ used meta-regression analysis to determine whether any of the four types of local

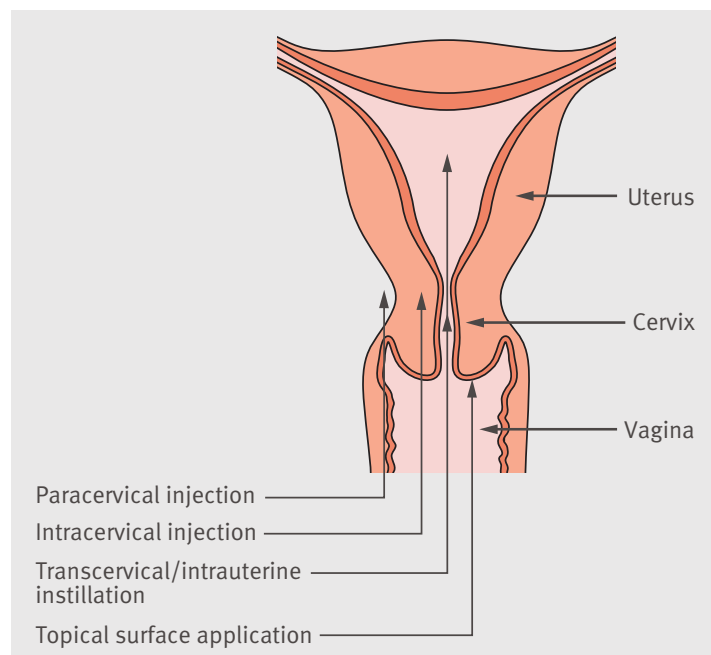

Fig 1 Different methods of administration of local anaesthetic for outpatient hysteroscopy 
Potentially relevant citations identified and screened for retrieval $(n=245)$ :

Medline, Embase, and CINAHL $(n=238)$

Cochrane Library $(n=7)$

\begin{tabular}{|c|c|c|c|c|}
\hline & \multicolumn{4}{|c|}{$\begin{array}{l}\text { Citations excluded }(n=210) \text { : } \\
\text { Inappropriate population, intervention, or outcome } \\
\text { measure }(n=151) \\
\text { Duplicates }(n=59)\end{array}$} \\
\hline \multicolumn{5}{|c|}{$\begin{array}{l}\text { Citations retrieved for more detailed evaluation }(n=37) \text { : } \\
\text { From electronic searches }(n=35) \\
\text { From references of retrieved papers }(n=2)\end{array}$} \\
\hline$\longrightarrow$ & \multicolumn{4}{|c|}{$\begin{array}{l}\text { Publications excluded }(n=17) \text { : } \\
\text { Not randomised controlled trial }(n=11) \\
\text { Data not explicitly reported }(n=3) \\
\text { Data reported in later, larger trials }(n=3)\end{array}$} \\
\hline \multicolumn{5}{|c|}{ Publications selected for appraisal $(n=20)$} \\
\hline Subgrou & $\begin{array}{l}\text { Inclu } \\
\text { syst } \\
\text { re }\end{array}$ & $\begin{array}{l}\text { luded in } \\
\text { tematic } \\
\text { eview }\end{array}$ & $\begin{array}{l}\text { Included in } \\
\text { meta-analysis } \\
\text { of pain }\end{array}$ & $\begin{array}{l}\text { Included in } \\
\text { meta-analysis } \\
\text { of vasovagal } \\
\text { episodes }\end{array}$ \\
\hline \multicolumn{5}{|c|}{ Intracervical } \\
\hline$v$ norm & al saline & 1 & 0 & 1 \\
\hline$v$ nil & & 3 & 2 & 0 \\
\hline $\begin{array}{c}v \text { norm } \\
\text { and } v\end{array}$ & $\begin{array}{l}\text { al saline } \\
\text { im tramadol }\end{array}$ & 1 & 1 & 0 \\
\hline \multicolumn{5}{|c|}{ Paracervical } \\
\hline$v$ norm & al saline & 2 & 2 & 2 \\
\hline$v$ nil & & 3 & 3 & 1 \\
\hline$v$ uteros & sacral & 1 & 0 & 0 \\
\hline$v$ consc & ious sedation & 1 & 0 & 1 \\
\hline \multicolumn{5}{|c|}{ Transcervical } \\
\hline$v$ norm & al saline & 3 & 3 & 2 \\
\hline $\begin{array}{l}v \text { norm } \\
\text { contai } \\
\text { anaes }\end{array}$ & $\begin{array}{l}\text { al saline } \\
\text { ining } \\
\text { thesia }\end{array}$ & 2 & 2 & 1 \\
\hline \multicolumn{5}{|l|}{ Topical } \\
\hline$v$ place & & 3 & 2 & 1 \\
\hline Total & & 20 & 15 & 9 \\
\hline
\end{tabular}

Fig 2 Study selection process for systematic review of local anaesthetic for pain relief during outpatient hysteroscopy

anaesthetic techniques was superior ${ }^{17}$ For the dichotomous outcome of vasovagal attacks we used the Peto method because of the low incidence of events in the studies. ${ }^{18}$ Analyses were performed with RevMan software $^{19}$ and Stata. ${ }^{20}$

\section{RESULTS}

\section{Study selection, details, and quality}

The literature search yielded 245 citations. Reviewing the reference lists yielded two further citations. Of these, 20 studies were considered eligible for inclusion in the review (fig 2). The inter-rater reliability for the study selection was good $(\kappa=0.9)$.

Tables 2, 3, and 4 show details of the study populations, intervention, outcome assessment, and data reporting. The quality of the studies varied with deficiencies in randomisation and blinding (fig 3).

Of the 20 selected studies, 18 reported data on local anaesthetic compared with placebo or nothing. One of these studies also reported data for a third randomised group of patients who received opiate analgesia (tramadol).$^{21}$ Of the two remaining studies, one compared use of local anaesthetic with conscious sedation (midazolam) ${ }^{22}$ and the other compared different local anaesthetic regimens (paracervical injection $v$ uterosacral ligament injection). ${ }^{23}$ Of the 18 papers reporting data for pain relief, we excluded three from meta-analysis; two because data were reported as the median value $^{24}$ or the mean but without standard deviation or standard error, ${ }^{25}$ precluding calculation of the standardised mean difference, and another because of differences in intervention between the groups in addition to the use of local anaesthetic. ${ }^{26}$ Most of the papers used continuous visual analogue scales (VAS) to assess pain; other studies used ordinal numerical or descriptive scales. Most results were reported as mean or median pain scores. One study used a descriptive scale ${ }^{27}$ and we applied numerical values to each category (none $=1$, mild $=2$, moderate $=3$, and severe $=4$ ) and used this to calculate the mean scores and standard deviations. ${ }^{28}$ One study reported raw data, ${ }^{21}$ from which we calculated the mean and standard deviation. ${ }^{28}$ The populations in the two studies ${ }^{2127}$ for which we calculated the mean and standard deviation were sufficiently large for us to approximate them to a normal distribution according to central limit theory. ${ }^{29}$ Another study reported the standard error, ${ }^{30}$ which we converted into the standard deviation. ${ }^{31}$

Nine of the selected studies provided data on vasovagal episodes. Four of the studies reported vasovagal attacks according to a strict definition based on heart rate, blood pressure, and symptoms ${ }^{14-1632}$; four reported vasovagal symptoms (such as faintness, nausea, pallor) ${ }^{2253033}$; and one reported a vasovagal attack in the complications but did not give any a priori definition of symptoms or signs. ${ }^{34}$

\section{Effect of local anaesthetic}

Meta-analysis of 15 studies showed that the use of local anaesthetic reduced the amount of pain experienced during outpatient hysteroscopy (standardised mean difference $-0.54,95 \%$ confidence interval -0.86 to $-0.23, \mathrm{I}^{2}=91 \%$ ) (fig 4). Meta-analysis of the studies subgrouped according to quality found that both poor and high quality studies showed a significant benefit with use of local anaesthetic $\left(-0.77,-1.45\right.$ to $-0.08, \mathrm{I}^{2}=95 \%$, and $-0.43,-0.73$ to $-0.12, \mathrm{I}^{2}=83 \%$, respectively) (fig 4 ). When we grouped the studies into subgroups, three studies examined intracervical injection, ${ }^{212735}$ five used paracervical injection, ${ }^{1516303637}$ five used transcervical application (topical into the uterine cavity), ${ }^{1432333839}$ and two applied the anaesthetic topically (topical to the cervix only). ${ }^{3440}$ The use of an intracervical injection of local anaesthetic significantly reduced pain $\left(-0.36,-0.61\right.$ to $\left.-0.10, \mathrm{I}^{2}=0 \%\right)$ (fig 4$)$. This finding, however, contrasted with one study included in the review but included not in the metaanalysis because of insufficient data, which found no significant effect of intracervical local anaesthetic on pain. ${ }^{25}$ To examine this conflicting result, we 
Table 2 | Characteristics of studies that used carbon dioxide as distension medium included in systematic review of use of local anaesthetic during outpatient hysteroscopy

\begin{tabular}{|c|c|c|c|c|c|}
\hline Study & Participants & Intervention & Comparison & Outcome measure & Data reported \\
\hline $\begin{array}{l}\text { Bellati }^{21} \text { (in } \\
\text { Italian, abstract } \\
\text { in English) }\end{array}$ & $\begin{array}{l}\text { Women undergoing diagnostic } \\
\text { outpatient hysteroscopy and } \\
\text { endometrial biopsy }\end{array}$ & $\begin{array}{l}\text { Intracervical injection of } 4 \mathrm{ml} 2 \% \\
\text { mepivicaine, } 5 \text { minutes before } \\
\text { procedure, } n=40\end{array}$ & $\begin{array}{l}\text { Group 1: tramadol } 100 \mathrm{mg} \text { im } \\
50 \text { minutes before procedure, } n=40 \text {; } \\
\text { group 2: nil, } n=40\end{array}$ & $\begin{array}{l}\text { Ordinal score 0-20 during } \\
\text { hysteroscopy }\end{array}$ & $\begin{array}{l}\text { Mean (SD) } \\
\text { calculated from } \\
\text { raw data }\end{array}$ \\
\hline Broadbent $^{27}$ & $\begin{array}{l}\text { Women undergoing diagnostic } \\
\text { outpatient hysteroscopy for } \\
\text { abnormal uterine bleeding. Patients } \\
\text { unable to tolerate procedure were } \\
\text { excluded }\end{array}$ & $\begin{array}{l}\text { Intracervical injection of } 10 \mathrm{ml} 1 \% \\
\text { lidocaine with } 1: 200000 \text { adrenaline, } \\
\text { at least } 5 \text { minutes before procedure, } \\
n=49\end{array}$ & $\begin{array}{l}\text { Same procedure but with } 10 \mathrm{ml} 0.9 \% \\
\text { saline, } \mathrm{n}=48\end{array}$ & $\begin{array}{l}\text { Pain defined by selecting a category } \\
\text { from none, mild, moderate, and } \\
\text { severe. Graded before, during, } \\
\text { immediately, and } 30 \text { minutes after }\end{array}$ & $\begin{array}{l}\text { Mean (SD) } \\
\text { calculated by } \\
\text { assigning } \\
\text { numerical value } \\
\text { to groups }\end{array}$ \\
\hline Cicinelli $1997^{14}$ & $\begin{array}{l}\text { Postmenopausal women undergoing } \\
\text { diagnostic hysteroscopy and } \\
\text { endometrial biopsy because of } \\
\text { endometrial bleeding }\end{array}$ & $\begin{array}{l}2 \mathrm{ml} 2 \% \text { mepivacaine injected } \\
\text { transcervically through os into } \\
\text { uterine cavity } 5 \text { minutes before } \\
\text { procedure, } \mathrm{n}=40\end{array}$ & $\begin{array}{l}\text { Same procedure but with } 2 \mathrm{ml} 0.9 \% \\
\text { saline, } n=40\end{array}$ & $\begin{array}{l}\text { VAS } 0-20 \text { completed before, during } \\
\text { and } 15 \text { minutes after procedure and } \\
\text { during endometrial biopsy }\end{array}$ & Mean (SD) \\
\hline Cicinelli $1998^{15}$ & $\begin{array}{l}\text { Postmenopausal women undergoing } \\
\text { diagnostic hysteroscopy and } \\
\text { endometrial biopsy because of } \\
\text { endometrial bleeding }\end{array}$ & $\begin{array}{l}\text { Paracenical block of } 10 \mathrm{ml} 1.5 \% \\
\text { mepivacaine } 10 \text { minutes before } \\
\text { procedure, } n=36\end{array}$ & $\begin{array}{l}\text { Same procedure but with } 10 \mathrm{ml} 0.9 \% \\
\text { saline, } n=36\end{array}$ & $\begin{array}{l}\text { VAS } 0-20 \text { completed before, during } \\
\text { and } 15 \text { minutes after procedure and } \\
\text { during endometrial biopsy }\end{array}$ & Mean (SD) \\
\hline Costello 38 & $\begin{array}{l}\text { Women referred for outpatient } \\
\text { hysteroscopy }\end{array}$ & $\begin{array}{l}\text { Scope passed into cervical os until } \\
\text { "snug." } 5 \mathrm{ml} 2 \% \text { lidocaine injected } \\
\text { through operating channel of scope. } \\
\text { Waited } 2 \text { minutes before procedure } \\
\text { continued, } n=49\end{array}$ & $\begin{array}{l}\text { Same procedure but with. } 5 \mathrm{ml} 0.9 \% \\
\text { saline, } n=50\end{array}$ & $\begin{array}{l}\text { VAS } 0-10 \mathrm{~cm} \text { to score pain during } \\
\text { procedure }\end{array}$ & Mean (SD) \\
\hline Davies $^{24}$ & $\begin{array}{l}\text { Women requiring outpatient } \\
\text { hysteroscopy. Exclusions: known } \\
\text { sensitivity to lidocaine, epilepsy, } \\
\text { impaired respiratory or cardiac } \\
\text { function, liver disease, treatment } \\
\text { with tricyclic antidepressants or } \\
\text { monoamine oxidase inhibitors }\end{array}$ & $\begin{array}{l}10 \% \text { lidocaine sprayed on to } \\
\text { endocervix and through cervical os } \\
\text { into uterine cavity, } 10 \text { sprays in total, } \\
n=60\end{array}$ & $\begin{array}{l}\text { Same procedure but with placebo } \\
\text { spray, } n=60\end{array}$ & $\begin{array}{l}\text { VAS } 10 \mathrm{~cm} \text { to score pain as } \\
\text { tenaculum was applied, nozzle of } \\
\text { spray inserted into canal, insertion of } \\
\text { scope, during procedure, during } \\
\text { biopsy, and } 5 \text { minutes after }\end{array}$ & $\begin{array}{l}\text { Median VAS } \\
\text { and } \\
\text { interquartile } \\
\text { ranges }\end{array}$ \\
\hline Esteve $^{35}$ & $\begin{array}{l}\text { Women attending for outpatient } \\
\text { hysteroscopy }\end{array}$ & $\begin{array}{l}\text { Intracervical injection of } 8 \mathrm{ml} 2 \% \\
\text { lidocaine, } n=34\end{array}$ & $\begin{array}{l}\text { Same procedure but with } 8 \mathrm{ml} 0.9 \% \\
\text { saline, } n=28\end{array}$ & $\begin{array}{l}\text { VAS } 0-10 \mathrm{~cm} \text { to score pain during } \\
\text { hysteroscopy, during biopsy, at end } \\
\text { of procedure, and } 30 \text { minutes after }\end{array}$ & Mean (SD) \\
\hline Giorda $^{30}$ & $\begin{array}{l}\text { All postmenopausal women referred } \\
\text { for diagnostic outpatient } \\
\text { hysteroscopy. Women who refused } \\
\text { to participate or had allergy to } \\
\text { anaesthesia, previous hysteroscopy, } \\
\text { and previous severe vagal reaction to } \\
\text { blind endometrial biopsy excluded }\end{array}$ & $\begin{array}{l}\text { Paracervical injection of } 20 \mathrm{ml} 1 \% \\
\text { mepivacaine at least } 5 \text { minutes } \\
\text { before procedure. Hysteroscopy } \\
\text { performed with } 5 \mathrm{~mm} \text { diameter } \\
\text { scope, } \mathrm{n}=121\end{array}$ & $\begin{array}{l}\text { Group 1: no paracervical injection, } \\
\text { hysteroscopy performed with } 5 \mathrm{~mm} \\
\text { scope; group 2: no paracervical } \\
\text { injection. hysteroscopy performed } \\
\text { with } 3.5 \mathrm{~mm} \text { scope, } \mathrm{n}=119\end{array}$ & $\begin{array}{l}\text { Visual numerical rating scale, range } \\
0-10 \text {, to score pain during procedure } \\
\text { only (patients who received } \\
\text { paracervical block asked to discount } \\
\text { the pain from injection) }\end{array}$ & $\begin{array}{l}\text { Mean. SD } \\
\text { calculated from } \\
\text { standard error }\end{array}$ \\
\hline Lau $1999^{16}$ & $\begin{array}{l}\text { Women undergoing diagnostic } \\
\text { outpatient hysteroscopy for } \\
\text { abnormal uterine bleeding }\end{array}$ & $\begin{array}{l}\text { Paracenical injection of } 10 \mathrm{ml} 2 \% \\
\text { lidocaine } 5 \text { minutes before } \\
\text { procedure, } n=49\end{array}$ & $\begin{array}{l}\text { Same procedure but with } 10 \mathrm{ml} 0.9 \% \\
\text { saline, } n=50\end{array}$ & $\begin{array}{l}\text { VAS } 10 \mathrm{~cm} \text { used to score pain when } \\
\text { tenaculum applied, after } \\
\text { paracervical injection, at } \\
\text { hysteroscopy insertion, during } \\
\text { hysteroscopy, after endometrial } \\
\text { biopsy, and } 30 \text { minutes after }\end{array}$ & Mean (SD) \\
\hline Lau $2000^{32}$ & $\begin{array}{l}\text { Women scheduled for diagnostic } \\
\text { outpatient hysteroscopy }\end{array}$ & $\begin{array}{l}5 \mathrm{ml} 2 \% \text { lidocaine instilled } \\
\text { transcervically into uterine cavity, } \\
\mathrm{n}=45\end{array}$ & $\begin{array}{l}\text { Same procedure but with } 5 \mathrm{ml} 0.9 \% \\
\text { saline, } n=44\end{array}$ & $\begin{array}{l}\text { VAS } 10 \mathrm{~cm} \text { used to score pain when } \\
\text { tenaculum applied, after the } \\
\text { paracervical injection, at } \\
\text { hysteroscopy insertion, during } \\
\text { hysteroscopy, after endometrial } \\
\text { biopsy, and } 30 \text { minutes after }\end{array}$ & Mean (SD) \\
\hline Makris $^{25}$ & $\begin{array}{l}\text { Women undergoing diagnostic } \\
\text { outpatient hysteroscopy, with or } \\
\text { without endometrial biopsy }\end{array}$ & $\begin{array}{l}\text { Intracervical injection of } 1-3 \mathrm{ml} 3 \% \\
\text { mepivacaine, } 3 \text { minutes before } \\
\text { procedure, } n=100\end{array}$ & $\begin{array}{l}\text { Same procedure but with } 1-3 \mathrm{ml} \\
0.9 \% \text { saline, } n=100\end{array}$ & $\begin{array}{l}\text { Ordinal scale } 0-10 \text {. Patients asked to } \\
\text { rate pain experienced during } \\
\text { hysteroscopy and at } 30 \text { and } \\
60 \text { minutes after procedure by } \\
\text { circling one number }\end{array}$ & $\begin{array}{l}\text { Mean reported. } \\
\text { Unable to } \\
\text { calculate SD }\end{array}$ \\
\hline Wong $^{40}$ & $\begin{array}{l}\text { Women referred for investigation of } \\
\text { abnormal uterine bleeding or } \\
\text { suspected endometrial pathology. } \\
\text { Women who spoke dialect (study } \\
\text { carried out in China) or had other } \\
\text { communication problems were } \\
\text { excluded }\end{array}$ & $\begin{array}{l}4 \mathrm{ml} \text { of } 2 \% \text { lidocaine rubbed over } \\
\text { cervix for } 20 \text { seconds immediately } \\
\text { before hysteroscopy, } n=250\end{array}$ & $\begin{array}{l}\text { Same procedure but with } 4 \mathrm{ml} \text { of inert } \\
\text { lubricant, } n=250\end{array}$ & $\begin{array}{l}\text { Patients graded severity of pain at } \\
1 \text { minute intervals with PPI scale. } \\
\text { Mean pain score, peak pain score, } \\
\text { and overall pain score, calculated as } \\
\text { were mean pain scores for each of } \\
\text { individual step of procedure }\end{array}$ & Mean (SD) \\
\hline
\end{tabular}

VAS= visual analogue scale, im=intramuscular, $\mathrm{PPI}=$ present pain intensity scale (verbal descriptors of pain ranked from 0-5 on numerical scale).

performed a sensitivity analysis excluding from the meta-analysis the study in which categorical data had been transformed. ${ }^{27}$ We found no significant reduction in pain with intracervical injection $(-0.35,-0.82$ to $\left.0.12, \mathrm{I}^{2}=48 \%\right)$.
The use of paracervical injection was associated with a significant reduction of pain $(-1.28,-2.22$ to -0.38 , $\mathrm{I}^{2}=97 \%$ ) (fig 4). The use of topically administered local anaesthetic did not ameliorate pain. Specifically, transcervical local anaesthetic did not significantly reduce 
Table $3 \mid$ Characteristics of studies that used normal saline as distension medium included in systematic review of use of local anaesthetic

\begin{tabular}{|c|c|c|c|c|c|}
\hline Study & Participants & Intervention & Comparison & Outcome measure & Data reported \\
\hline Al-Sunaidi ${ }^{36}$ & $\begin{array}{l}\text { Women undergoing diagnostic outpatient } \\
\text { hysteroscopy for evaluation of uterine cavity. } \\
\text { Exclusions: women needing operative } \\
\text { hysteroscopy under GA, positive chlamydia } \\
\text { culture, pregnancy, or allergy to local } \\
\text { anaesthetic }\end{array}$ & $\begin{array}{l}\text { Intracervical injection of } 2 \mathrm{ml} 0.5 \% \\
\text { bupivacaine and paracervical } \\
\text { injection of } 8 \mathrm{ml} 0.5 \% \\
\text { bupivacaine, } 5 \text { minutes before } \\
\text { procedure, } \mathrm{n}=42\end{array}$ & $\begin{array}{l}\text { Intracervical injection of } 2 \mathrm{ml} 0.5 \% \\
\text { bupivacaine, } 5 \text { minutes before } \\
\text { procedure. } n=42\end{array}$ & $\begin{array}{l}\text { VAS } 0-10 \text {, completed during } \\
\text { procedure and at } 10,30 \text {, and } \\
60 \text { minutes after }\end{array}$ & Mean (SD) \\
\hline Guida $^{22}$ & $\begin{array}{l}\text { Women undergoing operative outpatient } \\
\text { hysteroscopy for surgically treatable lesions } \\
\text { associated with infertility or abnormal uterine } \\
\text { bleeding }\end{array}$ & $\begin{array}{l}\text { Paracervical injection of } 10 \mathrm{ml} 1 \% \\
\text { mepivacaine, } \mathrm{n}=82\end{array}$ & $\begin{array}{l}\text { Conscious sedation with } 0.5 \mathrm{mg} \\
\text { atropine iv, } 0.25 \mathrm{mg} \text { fentanyl iv, } \\
\text { and } 2 \mathrm{mg} \text { midazolam iv, } \mathrm{n}=84\end{array}$ & $\begin{array}{l}5 \mathrm{~cm} \text { VAS used during, } \\
\text { immediately after, } 15 \text {, and } \\
60 \text { minutes after and } 24 \text { and } 72 \\
\text { hours after procedure }\end{array}$ & Mean (SD) \\
\hline Kabli $^{39}$ & $\begin{array}{l}\text { Infertile women undergoing outpatient } \\
\text { hysteroscopy. Women needing operative } \\
\text { hysteroscopy under GA, positive chlamydia } \\
\text { culture, pregnancy, or allergy to local } \\
\text { anaesthetic were excluded. }\end{array}$ & $\begin{array}{l}\text { Intracervical injection of } 2 \mathrm{ml} 1 \% \\
\text { lidocaine and distension media } \\
\text { with } 18 \mathrm{ml} \text { lidocaine } / 250 \mathrm{ml} \\
\text { saline, } \mathrm{n}=42\end{array}$ & $\begin{array}{l}\text { Intracenvical injection of } 2 \mathrm{ml} 1 \% \\
\text { lidocaine, } \mathrm{n}=36\end{array}$ & $\begin{array}{l}\text { VAS } 0-10 \text { used to score pain after } \\
\text { hysteroscopy, after endometrial } \\
\text { biopsy, and at } 10,30 \text {, and } \\
60 \text { minutes after procedure }\end{array}$ & Mean (SD) \\
\hline Sagiv $^{26}$ & $\begin{array}{l}\text { Women undergoing diagnostic outpatient } \\
\text { hysteroscopy }\end{array}$ & $\begin{array}{l}\text { Intracervical injection of } 10 \mathrm{ml} \mathrm{3 \%} \\
\text { mepivacaine, } \mathrm{n}=47\end{array}$ & $\begin{array}{l}\text { Vaginoscopy (performed without } \\
\text { speculum or anaesthesia), } n=83\end{array}$ & $\begin{array}{l}\text { VAS } 0-10 \mathrm{~cm} \text { used to score pain } \\
\text { immediately and } 15 \text { minutes after } \\
\text { hysteroscopy }\end{array}$ & Mean (SD) \\
\hline Shankar $^{33}$ & $\begin{array}{l}\text { Women with abnormal uterine bleeding } \\
\text { referred by GP for diagnostic outpatient } \\
\text { hysteroscopy. Exclusions: unable to visualise } \\
\text { cervix or severe cervical stenosis }\end{array}$ & $\begin{array}{l}\text { Distension media containing } \\
40 \mathrm{ml} 2 \% \text { lidocaine } / 500 \mathrm{ml} 0.9 \% \\
\text { saline, } \mathrm{n}=100\end{array}$ & $\begin{array}{l}\text { Distension media of } 0.9 \% \text { saline } \\
\text { only, } n=100\end{array}$ & Pain scored with VAS $0-10$, and PPI & Mean (SD) \\
\hline Soriano $^{34}$ & $\begin{array}{l}\text { Women undergoing diagnostic hysteroscopy } \\
\text { for abnormal uterine bleeding or infertility. } \\
\text { Women with menorrhagia at time of } \\
\text { procedure, sensitivity to lidocaine, epilepsy, } \\
\text { impaired respiratory or cardiac function, and } \\
\text { active liver disease excluded }\end{array}$ & $\begin{array}{l}5 \% \text { lidocaine sprayed on to } \\
\text { endocervix and into cervical canal, } \\
\text { ( } 3 \text { sprays in total) } 5 \text { minutes before } \\
\text { procedure, } n=62\end{array}$ & $\begin{array}{l}\text { Same procedure with placebo } \\
\text { spray, } n=56\end{array}$ & $\begin{array}{l}\text { VAS } 0-10 \mathrm{~cm} \text { to score pain } \\
\text { experienced during procedure }\end{array}$ & Mean (SD) \\
\hline
\end{tabular}

$\mathrm{GA}=$ general anaesthesia; $\mathrm{PPI}=$ present pain intensity scale (verbal descriptors of pain ranked from 0-5 on numerical scale).

the amount of pain experienced $(-0.11,-0.31$ to 0.10 , $\mathrm{I}^{2}=27 \%$ ) (fig 4$)$. Similarly, there was no significant alleviation of pain when local anaesthetic was applied topically to the cervix $\left(-0.32,-0.97\right.$ to $\left.0.33, \mathrm{I}^{2}=90 \%\right)$ (fig 4$)$, though meta-analysis showed substantial heterogeneity. A further study included in the review, which could not be used for the meta-analysis because it reported median visual analogue scale scores, showed no significant difference between topical cervical local anaesthetic and placebo for the hysteroscopy but did show a significant reduction in pain in the local anaesthetic group during application of a cervical tenaculum $(\mathrm{P}=0.005) .{ }^{24}$

We performed a further meta-analysis of injectable local anaesthetic (intracervical and paracervical) compared with topical application (transcervical to uterine cavity and topical to the cervix). This showed a benefit with injectable local anaesthetics $(-0.92,-1.51$ to $\left.-0.33, \mathrm{I}^{2}=94 \%\right)$ but not topical ones $(-0.17,-0.38$ to $\left.0.03, \mathrm{I}^{2}=62 \%\right)$. Meta-regression analysis showed that paracervical injection was significantly more effective than the other methods of anaesthesia $(\mathrm{P}=0.048)$.

One study compared two methods of cervical block and found no significant difference in pain between a paracervical and a uterosacral ligament local block $(\mathrm{P}<0.65){ }^{23}$ Two studies compared local anaesthetic with other medication. ${ }^{2122}$ The first compared intracervical local anaesthetic with a control group (data used in meta-analysis) and with intramuscular injection of $100 \mathrm{mg}$ tramadol. Tramadol was significantly better than intracervical block at reducing the amount of pain experienced during hysteroscopy $(\mathrm{P}=0.001) .{ }^{21}$ The second study compared paracervical injection of local anaesthetic with the use of conscious sedation for operative hysteroscopy and found no significant difference in the pain experienced between the two groups. ${ }^{22}$

\section{Vasovagal episodes}

There was no significant difference in the incidence of vasovagal episodes between local anaesthetic and control (nil, normal saline, placebo, conscious sedation) groups $(\mathrm{P}=0.09$, fig 5$)$, regardless of definition of vasovagal reaction.

\section{DISCUSSION}

Local anaesthetic reduces the pain experienced by women during outpatient hysteroscopy. This occurs with paracervical and intracervical injections of anaesthetic but not with transcervical and topical application. Paracervical injection seems to be the most effective method of administering local anaesthetic for the procedure. Local anaesthetic did not significantly reduce the incidence of vasovagal attacks during outpatient hysteroscopy, but there was a beneficial trend.

\section{Strengths and limitations}

Many aspects of the review lead us to believe that our results are valid. Firstly, we formulated a clinically focused question and then performed comprehensive searches that encompassed multiple online databases as well as searching of the reference sections of relevant studies. We had no language restriction, and we used broad search terms to avoid making the question too specific to be adequately sensitive. We did not seek any unpublished data and therefore there is a risk of 
Table $4 \mid$ Characteristics of studies that used other distension media* included in systematic review of use of local anaesthetic

\begin{tabular}{|c|c|c|c|c|c|}
\hline Study & Participants & Intervention† & Comparison & Outcome measure & Data reported \\
\hline \multicolumn{6}{|c|}{ Distension medium $1.5 \%$ glycine } \\
\hline Vercellini ${ }^{37}$ & $\begin{array}{l}\text { Premenopausal (FSH }<30 \mathrm{mIU} / \mathrm{ml} \text { ) non- } \\
\text { pregnant (negative } \beta \text {-hCG test) women } \\
\text { referred for investigation of excessive uterine } \\
\text { bleeding of for } \geq 3 \text { months. Women with } \\
\text { genital infection, previous cervical surgery or } \\
\text { hysteroscopy, severe cardiac disease, and } \\
\text { known sensitivity to local anaesthetics were } \\
\text { excluded }\end{array}$ & $\begin{array}{l}\text { Paracervical injection of } 1 \% \\
\text { mepivacaine more than } \\
5 \text { minutes before procedure, } \\
n=87\end{array}$ & No anaesthesia, $n=90$ & $\begin{array}{l}10 \text { point VAS used to score pain } \\
\text { during hysteroscopy and } \\
\text { endometrial biopsy }\end{array}$ & Mean (SD) \\
\hline \multicolumn{6}{|c|}{ Distension medium not stated } \\
\hline Finikiotis $^{13}$ & $\begin{array}{l}\text { Patients referred from GPs and from other } \\
\text { gynaecologists for investigation of various } \\
\text { gynaecological complaints }\end{array}$ & $\begin{array}{l}\text { Paracervical injection of } 16 \text { - } \\
20 \mathrm{ml} 1 \% \text { lidocaine, } n=60\end{array}$ & $\begin{array}{l}\text { Uterosacral injection of } 2 \mathrm{ml} \\
2 \% \text { lidocaine with 1:80 } 000 \\
\text { adrenaline, } n=60\end{array}$ & $\begin{array}{l}\text { VAS } 0-10 \mathrm{~cm} \text { to score pain during } \\
\text { procedure. Reported as No of } \\
\text { patients selecting VAS 0-3.3, } \\
3.4-6.3 \text {, and } 6.4-10.0\end{array}$ & $\begin{array}{l}\text { Mean (SD) calculated from } \\
\text { mean value of each category }\end{array}$ \\
\hline
\end{tabular}

VAS=visual analogue scale, GP=general practitioner.

${ }^{*}$ Other than carbon dioxide or normal saline.

fFor consistency the group receiving local anaesthetic (or combination of anaesthetics) are considered as intervention group even if that was not the case in original study.

publication bias. A funnel plot created to explore the possibility of publication bias indicated that we might have missed studies that report no benefit of using local anaesthetic for outpatient hysteroscopy. We restricted study design to randomised controlled trials to minimise selection bias. We were unable to explore reasons for heterogeneity in the subgroups by method of administration because of insufficient power caused by the small number of studies per subgroup. We graded the quality of our studies in subgroups, according to strict predetermined criteria, to examine for the overall heterogeneity. Heterogeneity was reduced in the high quality subgroup, but $\mathrm{I}^{2}$ was still $83 \%$. Metaanalysis of the high quality studies found a significant reduction in pain with the use of local anaesthetic, a finding that was consistent with and thus supportive of our overall findings. Intracervical injection of local anaesthetic was associated with a significant reduction in pain during outpatient hysteroscopy, but the strength of this finding is limited. This is because a sensitivity analysis excluding a study in which categorical data had been transformed showed no beneficial effect of intracervical injection, although this finding was associated with increased heterogeneity.

\section{Comparison with other studies}

To our knowledge, this is the only systematic review to assess the effect of local anaesthetic on pain during outpatient hysteroscopy. A Cochrane review assessed the use of paracervical injection for various obstetric and gynaecological procedures, including hysteroscopy, endometrial biopsy, fractional curettage, vacuum aspiration, suction termination of pregnancy, or evacuation of retained products of conception and bimanual removal of retained placenta. ${ }^{4}$ Only three studies involving hysteroscopy were included in the review and only two in meta-analysis. The conclusion that the use of paracervical injection does not reduce the pain of "uterine intervention" cannot be applied specifically to hysteroscopy. Our meta-analysis contains five studies assessing paracervical anaesthesia in hysteroscopy and so has greater power, adding weight to our findings. Moreover, intracervical and topical administration of local anaesthesia is more commonly used in ambulatory hysteroscopy than paracervical approaches. ${ }^{41}$ Our review assesses all routes of administration of local anaesthetic, thereby providing relevant guidance to clinicians for one of the most common interventions in gynaecology.

\section{Clinical implications of the review}

Injectable, preferably paracervical, administration of local anaesthetic should be used for women undergoing hysteroscopy as outpatients to reduce the amount of pain experienced. Topical application of local anaesthetic does not reduce the pain of the hysteroscopy but should be used when a tenaculum is applied to the cervix. Only one study examined the use of local anaesthetic for operative hysteroscopy ${ }^{22}$ and therefore our results do not adequately address the benefit of local anaesthetic in this variation of the procedure. Although our conclusions show a benefit of using local anaesthetic, we could not review data on harms because this was not explicitly reported by most studies except when they referred to symptoms caused by vagal stimulation (hypotension, bradycardia, nausea, vomiting, etc). Similar symptoms, however, might arise from intravasation of injected local

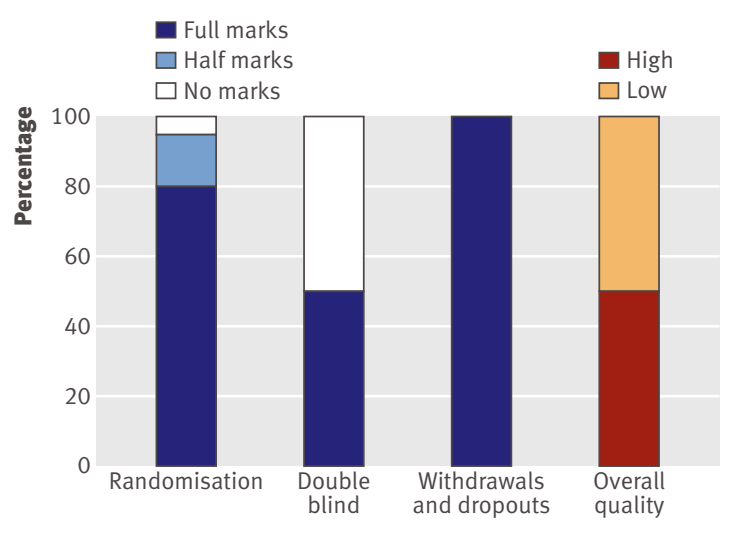

Fig 3 | Jadad quality assessment of studies examining use of local anaesthetic for outpatient hysteroscopy 


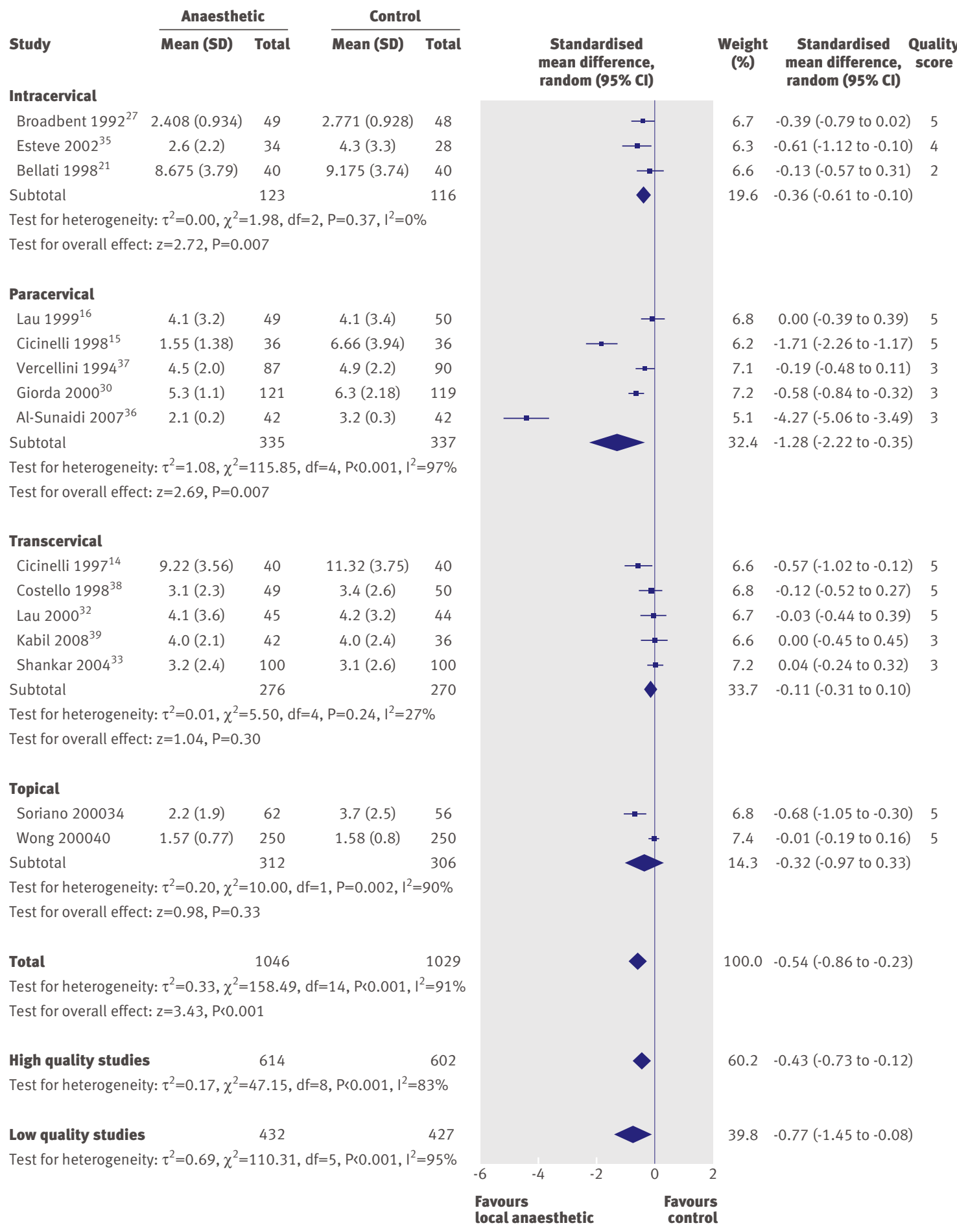

Fig 4 | Effect of local anaesthetic on pain during outpatient hysteroscopy, according to method of administration and quality of study. Figures are mean (SMD) pain scores

anaesthetic. Therefore side effects resulting from the use of local anaesthetic for outpatient hysteroscopy are likely to be underestimated. For example, the time taken to perform the block prolongs the procedure, and the pain scores might not take into account the pain experienced during injection of local anaesthetic, in itself a painful procedure. In fact one study found that a vaginoscopic approach to hysteroscopy was significantly less painful than having the procedure done traditionally with a vaginal speculum and a local anaesthetic block. ${ }^{26}$

Outpatient hysteroscopy is a multi-faceted procedure, and there are many factors that contribute towards pain. These can be categorised into factors related to the patient (such as menopausal status, reason for hysteroscopy) and procedural factors (such as the type of distension media, use of a speculum, use of a rigid or flexible hysteroscope). The small number of 


\begin{tabular}{|c|c|c|c|c|c|c|}
\hline Study & Anaesthetic & Control & $\begin{array}{l}\text { Peto odd } \\
\text { random ( }\end{array}$ & $\begin{array}{l}\text { ds ratio, } \\
(95 \% \mathrm{Cl})\end{array}$ & $\begin{array}{c}\text { Weight } \\
\text { (\%) }\end{array}$ & $\begin{array}{l}\text { Peto odds ratio, } \\
\text { random }(95 \% \mathrm{Cl})\end{array}$ \\
\hline Cicinelli $1997^{14}$ & $2 / 40$ & $13 / 40$ & $\rightarrow$ & & 14.5 & $0.17(0.06$ to 0.51$)$ \\
\hline Cicinelli $1998^{15}$ & $0 / 36$ & $9 / 36$ & $\longrightarrow$ & & 9.4 & $0.10(0.03$ to 0.42$)$ \\
\hline Giorda $2000^{30}$ & $8 / 121$ & $6 / 119$ & & & 15.5 & $1.33(0.45$ to 3.90$)$ \\
\hline Guida $2003^{22}$ & $7 / 82$ & $9 / 84$ & & & 17.1 & $0.78(0.28$ to 2.18$)$ \\
\hline Lau $2000^{32}$ & $3 / 45$ & $3 / 44$ & - &  & 6.6 & 0.98 (0.19 to 5.07$)$ \\
\hline Lau $1999^{16}$ & $15 / 49$ & $5 / 50$ & & $\rightarrow$ & 18.9 & 3.55 (1.34 to 9.41$)$ \\
\hline Makris $2001^{25}$ & $3 / 100$ & $8 / 100$ & - & & 12.3 & $0.38(0.11$ to 1.29$)$ \\
\hline Shankar $2004^{33}$ & $2 / 100$ & $2 / 100$ & & 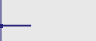 & 4.6 & $1.00(0.14$ to 7.21$)$ \\
\hline Soriano $2000^{34}$ & $0 / 62$ & $1 / 56$ & & - & 1.2 & $0.12(0.00$ to 6.16$)$ \\
\hline Total $(95 \% \mathrm{Cl})$ & $40 / 635$ & $56 / 629$ & $\bullet$ & & 100.0 & $0.69(0.45$ to 1.05$)$ \\
\hline \multicolumn{7}{|c|}{ Test for heterogeneity: $\chi^{2}=27.45, \mathrm{df}=8, \mathrm{P}<0.001, \mathrm{I}^{2}=71 \%$} \\
\hline \multirow{2}{*}{\multicolumn{2}{|c|}{ Test for overall effect: $z=1.72, P=0.09$}} & \multicolumn{4}{|c|}{$0 \quad 1000$} & \\
\hline & & \multicolumn{2}{|r|}{$\begin{array}{l}\text { Favours } \\
\text { local } \\
\text { anaesthetic }\end{array}$} & \multicolumn{2}{|c|}{$\begin{array}{l}\text { Favours } \\
\text { control }\end{array}$} & \\
\hline
\end{tabular}

Fig 5 | Incidence of vasovagal episodes in studies examining use of local anaesthetic for outpatient hysteroscopy local anaesthetic for every patient who undergoes an outpatient hysteroscopy.

There is a need for large trials comparing how the different hysteroscopic techniques (such as vaginoscopy versus a traditional hysteroscopy with or without local anaesthesia, type of distension media, use of a flexible or rigid scope, cervical preparation) affect pain, feasibility, and the incidence of vasovagal episodes during outpatient hysteroscopy. Such trials should explicitly define and standardise the procedure and systematically examine acceptability and quality of life, in addition to alleviation of pain. These qualitative outcomes can then be correlated with pain scores to see if any reported reduction in pain during outpatient hysteroscopy is actually clinically meaningful. Studies also need to look at patients' factors, such as parity and menopausal status, to determine case selection - that is, who will benefit the most from routine administration of injectable local cervical anaesthetics. Research trials should also evaluate administration of local anaesthetic and hysteroscopic technique in operative outpatient hysteroscopic surgery, which is becoming increasingly prevalent with technological advances in endoscopic instrumentation. ${ }^{41-43}$

Contributors: NAMC and TJC were involved in acquisition of data. NAMC undertook the analysis and interpretation of data and drafted the manuscript. TJC and KSK contributed to the critical revision of the manuscript and final review before publication. TJC is guarantor. Funding: This research received no specific grant from any funding agency in the public, commercial, or not-for-profit sectors

Competing interests: None declared.

Ethical approval: Not required.

Data sharing: No additional data available. variation and tended to be low anyway. Selection of individual cases must be considered as important in the assessment of who will benefit the most from the use of local anaesthetic. Parous premenopausal women are less likely to benefit as they probably have less narrowing of the cervical canal, whereas nulliparous postmenopausal women, who will almost certainly have a degree of cervical stenosis, might benefit greatly. Our results cannot quantify this benefit. It might be that altering aspects of the procedure (such as vaginoscopy, warming the liquid distension media, distension pressures) can reduce the pain considerably without the use of a local anaesthetic injection. There are obvious cost implications (for equipment and medication, as well as reducing the number of people seen in clinic) of using

\section{WHAT IS ALREADY KNOWN ON THIS TOPIC}

Ambulatory hysteroscopy is a common, safe, feasible, and accurate procedure for diagnosing intrauterine pathology

Individual studies examining the effect of local anaesthetics have provided conflicting results

\section{WHAT THIS STUDY ADDS}

Injectable local anaesthetics, particularly paracervical injections, are the most effective methods of reducing the pain of outpatient hysteroscopy

Topical administration of local anaesthetic does not significantly reduce the pain experienced during outpatient hysteroscopy

Alternative methods of reducing pain (such as vaginoscopy) need to be evaluated
1 Clark TJ, Voit D, Gupta JK, Hyde C, Song F, Khan KS. Accuracy of hysteroscopy in the diagnosis of endometrial cancer and hyperplasia: a systematic quantitative review. JAMA 2002;288:1610-21.

2 Royal College of Obstetricians and Gynaecologists. Standards for gynaecology. Report of a working party. RCOG Press, 2008.

3 Yang J, Vollenhoven B. Pain control in outpatient hysteroscopy. Obstet Gynecol Surv 2002;57:693-702.

4 Tangsiriwatthana T, Sangkomkamhang US, Lumbiganon P, Laopaiboon M. Paracenvical local anaesthesia for cervical dilatation and uterine intervention. Cochrane Database Syst Rev 2009;(1):CD005056.

5 Centre for Reviews and Dissemination (CRD). Systematic reviews: CRD's guidance for undertaking reviews in health care. CRD, University of York, 2009.

6 Cochrane Collaboration. Cochrane Collaboration handbook. 2008. www.cochrane.org/resources/handbook/.

7 Zupi E, Luciano AA, Valli E, Marconi D, Maneschi F, Romanini C. The use of topical anesthesia in diagnostic hysteroscopy and endometrial biopsy. Fertil Steril 1995;63:414-6.

8 Hong JY, Kim J. Use of paracenvical analgesia for outpatien hysteroscopic surgery: a randomized, double-blind, placebocontrolled study. Ambul Surg 2006;12:181-5.

9 Landis JR, Koch GG. The measurement of observer agreement for categorical data. Biometrics 1977;33:159-74.

10 Moher D, Jadad AR, Nichol G, Penman M, Tugwell P, Walsh S. Assessing the quality of randomized controlled trials: an annotated bibliography of scales and checklists. Control Clinl Trials 1995;16:62-73.

11 Jadad AR, Moore RA, Carroll D, Jenkinson C, Reynolds DIM, Gavaghan DJ, et al. Assessing the quality of reports of randomized clinical trials: is blinding necessary? Control Clinl Trials 1996;17:1-12.

12 Khan KS, Daya S, Jadad A. The importance of quality of primary studies in producing unbiased systematic reviews. Arch Intern Med 1996;156:661-6.

13 Finikiotis G. Side-effects and complications of outpatient hysteroscopy. Aust N Z J Obstet Gynaecol 1993;33:61-2. 
14 Cicinelli E, Didonna T, Ambrosi G, Schonauer LM, Fiore G, Matteo MG. Topical anaesthesia for diagnostic hysteroscopy and endometrial biopsy in postmenopausal women: a randomised placebocontrolled double-blind study. Br J Obstet Gynaecol 1997;104:316-9.

15 Cicinelli E, Didonna T, Schonauer LM, Stragapede S, Falco N, Pansini N. Paracervical anesthesia for hysteroscopy and endometrial biopsy in postmenopausal women. A randomized, double-blind, placebo-controlled study. J Reprod Med 1998;43:1014-8.

16 Lau WC, Lo WK, Tam WH, Yuen PM. Paracervical anaesthesia in outpatient hysteroscopy: a randomised double-blind placebocontrolled trial. Br J Obstet Gynaecol 1999;106:356-9.

17 Sterne JA, Juni P, Schulz KF, Altman DG, Bartlett C, Egger M. Statistical methods for assessing the influence of study characteristics on treatment effects in 'meta-epidemiological' research. Stat Med 2002;21:1513-24.

18 Bradburn MJ, Deeks JJ, Berlin JA, Russell LA. Much ado about nothing a comparison of the performance of meta-analytical methods with rare events. Stat Med 2007;26:53-77.

19 RevMan 5 [computer program]. Version 5. Nordic Cochrane Centre, 2008.

20 Stata Statistical software [computer program]. Version 8.2. College Station, Texas: StataCorp LP, 2004.

21 Bellati U, Bonaventura A, Costanza L, Zulli S, Gentile C. Tramadol hydrochloride versus mepivacaine hydrochloride: comparison between two analgesic procedures in hysteroscopy. Giornale Italiano di Ostetricia e Ginecologia 1998;20:469-72.

22 Guida M, Pellicano M, Zullo F, Acunzo G, Lavitola G, Palomba S, et al. Outpatient operative hysteroscopy with bipolar electrode: a prospective multicentre randomized study between local anaesthesia and conscious sedation. Hum Reprod 2003;18:840-3

23 Finikiotis G, Tsocanos S. Outpatient hysteroscopy: a comparison of 2 methods of local analgesia. Aust N Z J Obstet Gynaecol 1992;32:373-4.

24 Davies A, Richardson RE, O’Connor H, Baskett TF, Nagele F, Magos AL. Lignocaine aerosol spray in outpatient hysteroscopy: a randomized double-blind placebo-controlled trial. Fertil Steril 1997;67:1019-23.

25 Makris N, Xygakis A, Dachlythras M, Prevedourakis C, Michalas S. Mepivacaine local cervical anesthesia for diagnostic hysteroscopy: a randomized placebo-controlled study. J Gynecol Surg 2001;17:7-11.

26 Sagiv R, Sadan O, Boaz M, Dishi M, Schechter E, Golan A. A new approach to office hysteroscopy compared with traditional hysteroscopy: a randomized controlled trial. Obstet Gynecol 2006;108:387-92.

27 Broadbent JAM, Hill NCW, Molnar BG, Rolfe KJ, Magos AL. Randomized placebo controlled trial to assess the role of intracervical lignocaine in outpatient hysteroscopy. Br J Obstet Gynaecol 1992;99:777-9.
28 Standard Deviation Calculator. 2009. http://easycalculation.com/ statistics/standard-deviation.php

29 Altman DG. Practical statistics for medical research. Chapman and Hall, 1991.

30 Giorda G, Scarabelli C, Franceschi S, Campagnutta E. Feasibility and pain control in outpatient hysteroscopy in postmenopausal women: a randomized trial. Acta Obstet Gynecol Scand 2000;79:593-7.

31 Berger V. Random samples. The probability problem solver: a complete solution guide to any textbook. Research and Education Association, 1996

32 Lau WC, Tam WH, Lo WK, Yuen PM. A randomised double-blind placebo-controlled trial of transcervical intrauterine local anaesthesia in outpatient hysteroscopy. Br J Obstet Gynaecol 2000;107:610-3.

33 Shankar M, Davidson A, Taub N, Habiba M. Randomised comparison of distension media for outpatient hysteroscopy. BJOG 2004;111:57-62.

34 Soriano D, Ajaj S, Chuong T, Deval B, Fauconnier A, Darai E. Lidocaine spray and outpatient hysteroscopy: randomized placebo-controlled trial. Obstet Gynecol 2000;96:661-4.

35 Esteve M, Schindler S, Machado SB, Borges SA, Santos CR, Coutinho $\mathrm{E}$. The efficacy of intracervical lidocaine in outpatient hysteroscopy. Gynaecol Endosc 2002;11:33-6.

36 Al-Sunaidi M, Tulandi T. A randomized trial comparing local intracenvical and combined local and paracenvical anesthesia in outpatient hysteroscopy. J Minim Invasive Gynecol 2007;14:153-5.

37 Vercellini P, Colombo A, Mauro F, Oldani S, Bramante T, Crosignani PG. Paracervical anesthesia for outpatient hysteroscopy. Fertil Steril 1994;62:1083-5.

38 Costello MF, Horrowitz SD, Williamson M. A prospective randomized double-blind placebo-controlled study of local anaesthetic injected through the hysteroscope for outpatient hysteroscopy and endometrial biopsy. Gynaecol Endosc 1998;7:121-6.

39 Kabli N, Tulandi T. A randomized trial of outpatient hysteroscopy with and without intrauterine anesthesia. J Minim Invasive Gynecol 2008;15:308-10.

40 Wong AY, Wong K, Tang LC. Stepwise pain score analysis of the effect of local lignocaine on outpatient hysteroscopy: a randomized, double-blind, placebo-controlled trial. Fertil Steril 2000;73:1234-7.

41 Clark TJ, Gupta JK. Handbook of outpatient hysteroscopy: a complete guide to diagnosis and therapy. Hodder Education, 2005.

42 Clark TJ, Mahajan D, Sunder P, Gupta JK. Hysteroscopic treatment of symptomatic submucous fibroids using a bipolar intrauterine system: a feasibility study. Eu J Obstet Gynecol Reprod Biol 2002;100:237-42.

43 Sinha D, Kalathy V, Gupta JK, Clark TJ. The feasibility, success and patient satisfaction associated with outpatient hysteroscopic sterilisation. BJOG 2007;114:676-83.

Accepted: 18 November 2009 